\title{
Chapter 3 \\ Post-earthquake Demolition \\ in Christchurch, New Zealand: \\ A Case-Study Towards Incorporating \\ Environmental Impacts in Demolition \\ Decisions
}

\section{R. E. Gonzalez, M. T. Stephens, C. Toma, K. J. Elwood, and D. Dowdell}

\begin{abstract}
The 2010/2011 Canterbury Earthquake Sequence resulted in severe loss and disruption in Christchurch, New Zealand due to liquefaction and damage from strong shaking. Following the earthquake, over $60 \%$ of concrete buildings with $3+$ stories in the Christchurch CBD were demolished, resulting in a widespread displacement of people and business, an excess of \$NZD 40 billion in losses, and significant environmental impacts from the demolition. Following the event, it was revealed that environmental impacts were not a direct consideration in demolition decision making. This paper provides a quantitative evaluation of the environmental impacts of the demolitions in Christchurch to highlight the importance of including environmental considerations when deciding between repair or demolition of a damaged building. First, the quantitative and qualitative factors that led to the demolitions following the Canterbury Earthquake Sequence are discussed to provide context for the argument that environmental impacts should be included in such considerations. Next, the environmental impacts of building demolitions in Christchurch are presented in terms of the embodied $\mathrm{CO}_{2}$ and energy in the building materials; the demolition process and waste disposal are not considered in this initial evaluation. Finally, a brief discussion on incorporating environmental impacts into the demolition decision making paradigm is presented. Moreover, consideration of environmental impacts of demolitions supports the need to move toward low-damage design in the future evolution of building codes.
\end{abstract}

R. E. Gonzalez (凶) · M. T. Stephens · C. Toma · K. J. Elwood

University of Auckland, Auckland 92019, New Zealand

e-mail: rgon868@aucklanduni.ac.nz

D. Dowdell

Building Research Association of New Zealand, Porirua 5240, New Zealand

(C) The Author(s) 2021

47

S. Akkar et al. (eds.), Advances in Assessment and Modeling of Earthquake Loss,

Springer Tracts in Civil Engineering,

https://doi.org/10.1007/978-3-030-68813-4_3 


\subsection{Introduction}

The 2010/2011 Canterbury Earthquake Sequence caused severe loss and disruption in Christchurch, New Zealand. The most damaging event (M6.2, 5-km deep, 10-km SE of the Christchurch Central Business District (CBD)) occurred 22 February 2011 and resulted in 185 fatalities and widespread impacts on the community including loss of land and infrastructure due to liquefaction and damage from strong shaking and a cordon (public exclusion zone) that restricted access to a majority of the CBD which resulted in a widespread displacement of people and businesses (Potter et al. 2015). In the fallout from the earthquake, over $60 \%$ of concrete buildings with $3+$ stories in the Christchurch CBD were demolished, resulting in an excess of \$NZD 40 billion in losses (Parker and Steenkamp 2012). The high rate of demolition, particularly among buildings with relatively little damage, highlighted the complex quantitative (e.g. building damage, year of construction, occupancy) and qualitative factors (e.g. insurance and legislation) that influence the repair-or-demolish decision faced by building owners following an event (Kim et al. 2017; Marquis et al. 2017). In addition, Marquis et al. (2017) highlighted that the environmental impacts associated with demolishing a damaged building prior to the end of its design life-in terms of embodied $\mathrm{CO}_{2}$ and energy, waste generation during demolition and greenhouse gas emissions resulting from the construction of a new building-were largely ignored in the decision-making process, which is contrary to the principles of sustainability advocated by stakeholders, policymakers, and the general public (Carbon Leadership Forum 2019; MBIE 2020).

To begin to highlight the importance of incorporating environmental considerations in demolition decision making following earthquakes, this paper presents a preliminary study that provides a quantitative evaluation of the environmental impacts of building demolitions in Christchurch following the Canterbury earthquakes. First, the quantitative and qualitative factors that led to the demolitions are discussed to provide context for the argument that environmental impacts should be included in such considerations. Next, the environmental impacts of building demolitions in Christchurch are presented in terms of embodied $\mathrm{CO}_{2}$ and energy in the building materials. Finally, a brief discussion on incorporating environmental impacts into the demolition decision making paradigm is presented. Note that this paper is intended as a preliminary investigation into the environmental impacts associated with the demolition of buildings following earthquakes. There are many complex factors that contribute to the total environmental impact of the decision to demolish or repair a building including: building materials, building age, construction processes, repair strategies (if repaired), demolition processes (if demolished), and waste disposal. Only the embodied $\mathrm{CO}_{2}$ and energy in the building materials are considered here. 


\subsection{Factors that Influenced Demolition Decisions in Christchurch}

The Christchurch CBD includes approximately 110 city blocks bounded by four avenues: Deans, Bealey, Fitzgerald, and Moorhouse as illustrated in Fig. 3.1. At the time of the earthquakes, there were approximately 3000 buildings within the CBD, consisting primarily of commercial, light industrial, and residential buildings (Kam and Pampanin 2011). The dominant multi-story typologies of commercial and multiunit residential buildings within the CBD were reinforced concrete moment frame and shear wall buildings designed to "modern" (mid-1980's and onwards) provisions for seismic resistance. From the perspective of design performance and life safety, these dominant typologies tended to perform satisfactorily during the earthquakes, with plastic hinges forming in discrete regions, allowing the buildings to dissipate energy and people to evacuate. Further, a large number of buildings within these typologies had relatively little damage following the event (refer to Fig. 3.3) (Kim et al. 2017). However, in September 2014, the Canterbury Earthquake Recovery Authority (CERA) reported that 150 "significant" buildings (generally commercial and multi-unit residential $5+$ storeys) had been demolished in the Christchurch CBD, representing approximately $65 \%$ of significant buildings in the CBD and immediately surrounding neighbourhoods (Marquis et al. 2017). The geographical distribution of building demolitions within the Christchurch CBD is shown in Fig. 3.1.

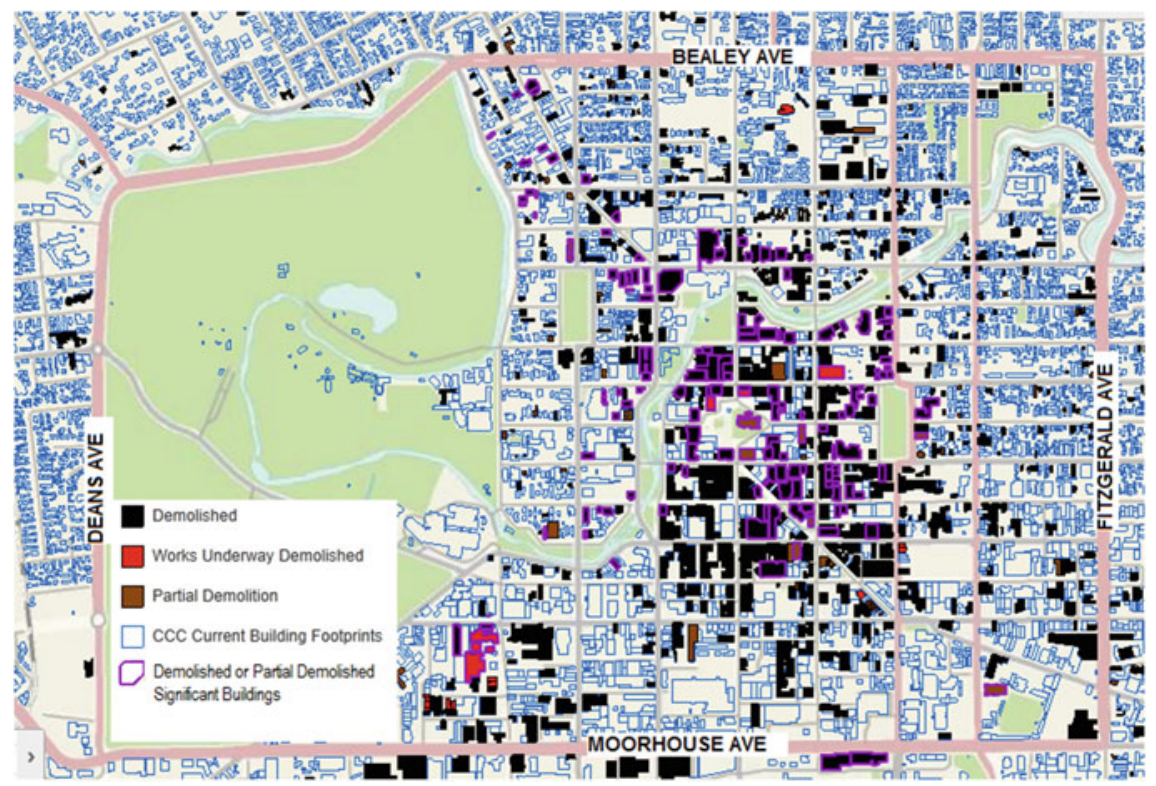

Fig. 3.1 Overview of building demolitions in christchurch CBD-November 2014 (figure reproduced from (Marquis et al. 2017)) 
The apparent disconnect between the level of damage and the high number of demolitions in Christchurch following the Canterbury Earthquake Sequence highlighted a lack of understanding surrounding the decision making process that leads to the demolition or repair of a structure - how was it that so many relatively lightly damaged buildings were demolished? To answer this question, several studies were initiated to evaluate the complex quantitative and qualitative parameters that factor into the decision to demolish a damaged building following an event (Kim et al. 2017; Marquis et al. 2017). These parameters are discussed in the following sections.

\subsubsection{Quantitative Factors}

Prior to the Canterbury Earthquake Sequence, there were no comprehensive quantitative studies on building demolitions following earthquakes. Kim et al. (2017) used a building data set consisting of $223 \mathrm{RC}$ moment frame and shear wall buildings (herein referred to as Building Set A) in Christchurch to identify quantitative variables that influenced post-earthquake decisions on whether to demolish or repair the buildings; these buildings represented approximately $88 \%$ of RC buildings of 3 storeys and higher in the Christchurch CBD. The variables for each building included building identification information, decision outcome, damage indicators, building condition, lateral load resisting system (LLRS), duration in cordon, year of construction, heritage status, footprint area, number of floors, and occupancy. A brief overview of the key parameters (Table 3.1) are discussed here, with more detailed descriptions of all parameters in reference material (Kim 2015; Kim et al. 2017).

The overall building demolition statistics for Building Set $A$ are shown in Fig. 3.2, while the building demolition statistics based on estimated damage, structural system, and duration in the cordon are shown in Fig. 3.3. A far more in-depth analysis of the

Table 3.1 Building parameters

\begin{tabular}{l|l}
\hline Parameter & Measure/description \\
\hline Decision outcome & Demolish, Repair, Unknown \\
\hline Damage indicators & Damage Ratio $^{1}$, Placard \\
\hline Building condition & $\% \mathrm{NBS}^{3}$, Design ductility \\
\hline Lateral Load Resisting System (LLRS) & $\begin{array}{l}\text { Moment Frame (MF), Shear Wall (SW), Moment } \\
\text { Frame and Infill (MFIF), Combined MF and SW }\end{array}$ \\
\hline Duration in cordon & Number of months in cordon \\
\hline $\begin{array}{l}{ }^{1} \text { Approximate visual estimate of building damage as a ratio of repair cost to replacement cost } \\
{ }^{2} \text { Usability of assessed building (Green-inspected, Yellow-Restricted use, Red-Unsafe) }\end{array}$ \\
$\begin{array}{l}{ }^{3} \text { Lateral load carrying capacity of a building as a function of the current building standard. Only } \\
\text { available for 15 buildings }\end{array}$ \\
${ }^{4}$ Only available for 15 buildings
\end{tabular}




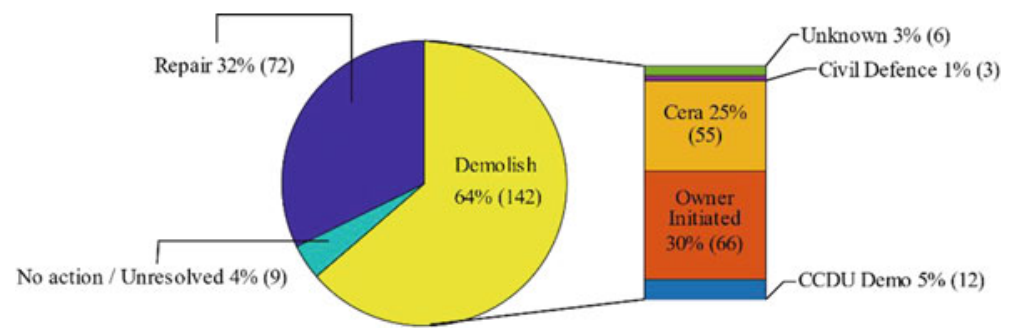

Fig. 3.2 a Overall demolition statistics for buildings in buildings set and $\mathbf{b}$ Party responsible for demolition

demolition data for the full range of parameters presented in Table 3.1 can be found in Kim (2015) and Kim et al. (2017).

A total of $64 \%$ of the buildings in the building set were demolished (142 buildings representing $64 \%$ of the total floor space), $32 \%$ were repaired (72 buildings representing $34 \%$ of the total floor space), and the fate of $4 \%$ were unknown at the time of data collection. As a fraction of the total number of buildings in the building set, $2 \%$ ( 3 buildings) were demolished immediately following the earthquake under instruction from Civil Defence for public safety, 5\% (12 buildings) were demolished to make way for other revitalisation projects, $25 \%$ (55 buildings) were demolished under instruction from CERA, and 30\% (66 buildings) were demolished based on the decision of the owner.

Figure 3.3a and $\mathrm{b}$ illustrates the building demolition statistics for varying levels of building damage as estimated using rapid assessments following the earthquake. The damage metrics evaluated included placard posting (green, yellow, red) and damage ratio (approximate visual estimate of building damage as a ratio of repair cost to replacement cost, excluding contents). Within the building set, 35\% (77 buildings) received green placards, $46 \%$ (103 buildings) received yellow placards, while $19 \%$ (43 buildings) received red placards. In addition, among 61\% (135 buildings) to have been assessed a relatively low damage ratio of $10 \%$ or less, $47 \%$ (63 buildings) were demolished. These statistics would appear to indicate that a significant number of buildings with relatively low damage were demolished.

To provide a slightly deeper look at the data here, Fig. $3.3 \mathrm{c}$ and $\mathrm{d}$ further segregate the data to evaluate the relationship between lateral load resisting system, damage ratio, duration in the cordon, and demolition statistics. RC moment frame and shear wall lateral load resisting systems were equally represented in the building data set ( $40 \%$ and $44 \%$ respectively), however moment frame buildings had a much higher rate of demolitions (75\%) than shear wall buildings (49\%). A high rate of demolition $(75 \%)$ was observed for buildings that remained in the cordon for more than 6 months, and an additional study (Chang et al. 2014) noted that being located within the cordon facilitated ease of demolition and may have led to a higher percentage of buildings in the cordon being demolished than would have been warranted based on damage alone. 


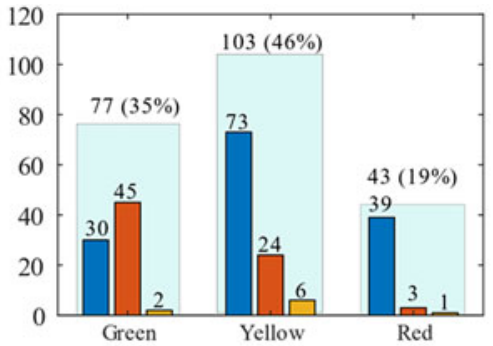

a) Placard

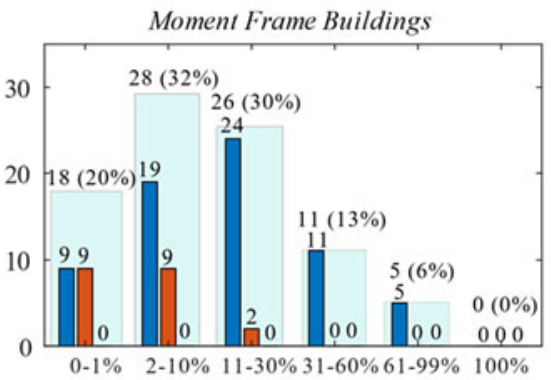

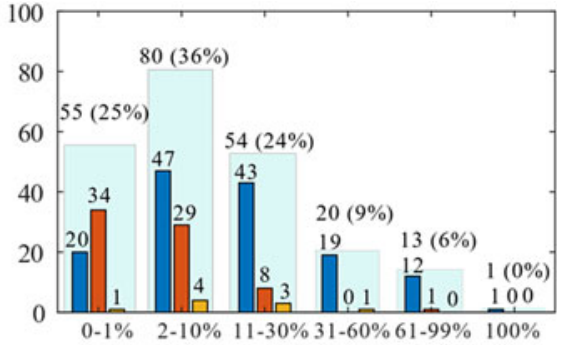

b) Damage Ratio

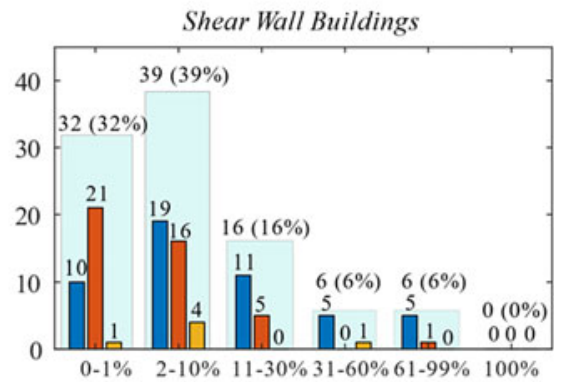

c) Lateral Load Resisting System

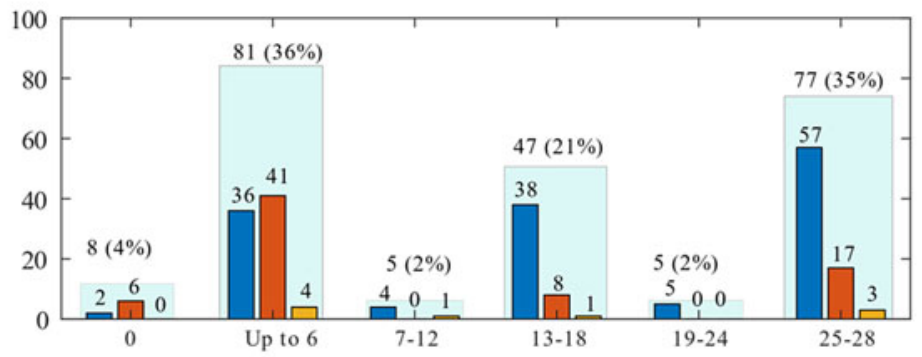

d) Time in Cordon (Months)

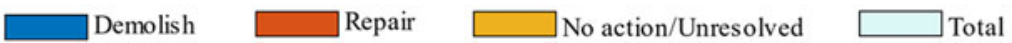

Fig. 3.3 a Placard placement demolition statistics, b Damage ratio demolition statistics, $\mathbf{c}$ Lateral load resisting system demolition statistics, and $\mathbf{d}$ Duration in cordon damage statistics for buildings in the building set

\subsubsection{Qualitative Factors}

The high demolition rate of relatively undamaged buildings in Christchurch (as summarised in the previous section) revealed complex and unique issues facing owners of commercial and multi-storey residential buildings when deciding the future of earthquake-impacted buildings. In particular, it became clear that while damage level is a good indicator of the seismic performance of a building, other multifaceted variables are involved in the ultimate decision to repair or demolish. 
Marquis et al. (2017) used a reduced building set of 15 buildings (herein referred to Building Set $B$ ) to explore the factors beyond structural damage that led to the decision to demolish or repair. The buildings in Building Set B were distributed throughout the Christchurch CBD and surrounding neighborhoods and were representative of the entire RC building stock within the CBD. Approximately half the buildings in Building Set B were repaired (7 buildings), while the remainder were demolished (8 buildings). Through this more detailed analysis, several qualitative factors that influence whether a building is demolished or repaired were revealed. Three of these factors are summarised here: (1) insurance, (2) building legislation, and (3) owner preference. Further details are provided in Marquis (2015) and Marquis et al. (2017).

\subsubsection{Insurance}

Approximately $80 \%$ of the economic loss from the Canterbury Earthquakes was covered by the insurance industry, which is considerably higher than other recent earthquakes worldwide (as illustrated in Fig. 3.4) (Bevere and Grollimund 2012). This high level of insurance penetration and unique policy wording played a critical role in the high rate of demolitions of relatively undamaged buildings in Christchurch (Kim et al. 2017; Marquis et al. 2017). The majority of commercial buildings in Christchurch were insured under a reinstatement policy, which entitles the policy owner to receive a repaired property which is largely the same in appearance, quality, and working order as "when new". However, following the event, it was revealed that the sum insured was frequently less than the actual rebuilding cost for most commercial properties, which meant the policy was not adequate to provide replacement of the building. The inadequate coverage of many commercial buildings in the CBD rendered technically viable repair and/or strengthening work uneconomic and resulted in a large number of cash settlement payouts and subsequent demolitions. All of the buildings in Building Set B cash settled. It should be noted that the unusually high rate of insurance penetration, combined with low deductibles and specific requirements in the reinstatement policies (e.g. the "as when new" clause), made insurance a relatively New Zealand specific factor in building demolition decisions following the Christchurch Earthquake (Marquis et al. 2017).

Fig. 3.4 Economic losses covered by insurance in recent earthquakes

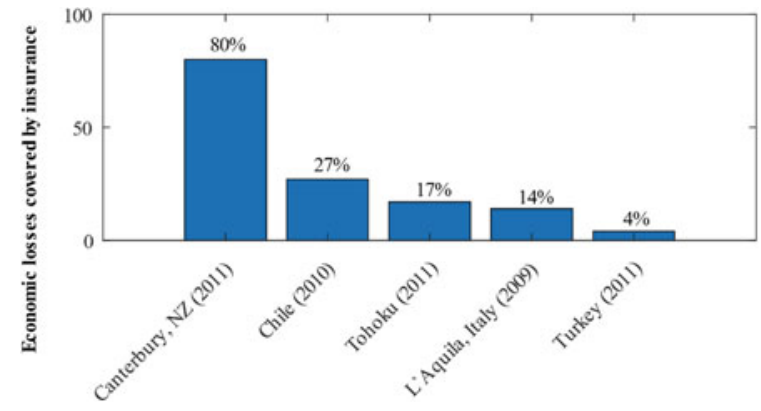




\subsubsection{Building Legislation}

The Building Act (2004) requires all new building work in New Zealand to comply with the New Zealand Building Code (Department of Building and Housing 2011). The Act applies to the construction of new buildings as well as the alteration and demolition of existing buildings. The Act deems a building to be earthquake prone if it has a lateral capacity $\leq 33 \%$ of a building designed and constructed to the current building code or New Building Standard (NBS). It should be noted that the Building Act does not explicitly consider the repair of earthquake-damaged buildings. Instead, earthquake damage is considered as an alteration, and as a result, the assessment and upgrade of fire systems and accessibility features are also triggered when earthquake damage is repaired, which can increase the effective repair costs substantially.

There were two changes to the building regulations following the earthquakes that influenced demolition decisions on earthquake prone buildings. First, the Christchurch City Council attempted to change the earthquake-prone building policy to require that building owners strengthen their buildings to $67 \%$ NBS, as opposed to $34 \%$ pre event. This change was struck down by a High Court decision in 2013 (and a Supreme Court decision released in December 2014), which stated that owners are only required to strengthen buildings to $34 \%$ NBS. However this reversal resulted in confusion as to (1) whether insurers were required to pay for the additional remediation (New Zealand Supreme Court 2014) and (2) whether building owners were required to upgrade to $67 \%$ NBS to receive a building consent for earthquake repairs. Second, the seismic hazard factor in Canterbury was increased from 0.22 to 0.3 to take into account heightened seismicity in the region following the earthquakes. This effectively forced down the \%NBS rating of many buildings in Christchurch. Both these changes have had a significant effect on post-earthquake decisions and the cost of the repair (and strengthening), which may have led to more building demolitions than would have occurred without the legislation changes.

The influence of $\%$ NBS on demolition decisions is illustrated using Building Set $B$ (Fig. 3.5). All buildings that were repaired in Building Set B, except one, had \%NBS values above $67 \%$, while all demolished buildings had \%NBS below $66 \%$, including two with \%NBS below 33\% (which would be designated as earthquake prone in New Zealand).

\subsubsection{Owner Preference}

Although insurance and building legislation certainly played a role in owners' decisions to demolish buildings following the earthquakes, it is important to highlight owner preference as a stand-alone factor that led to demolitions due to the relatively high rate of owner-initiated demolitions (as illustrated in Fig. 3.2). In general, owner preference with regard to demolition was informed by both pre-earthquake economic conditions as well as unique decision-making strategies to avoid economic loss post-event (Marquis et al. 2017). Prior to the event, there was a significant surplus of commercial space in the Christchurch CBD, which contributed to a low 


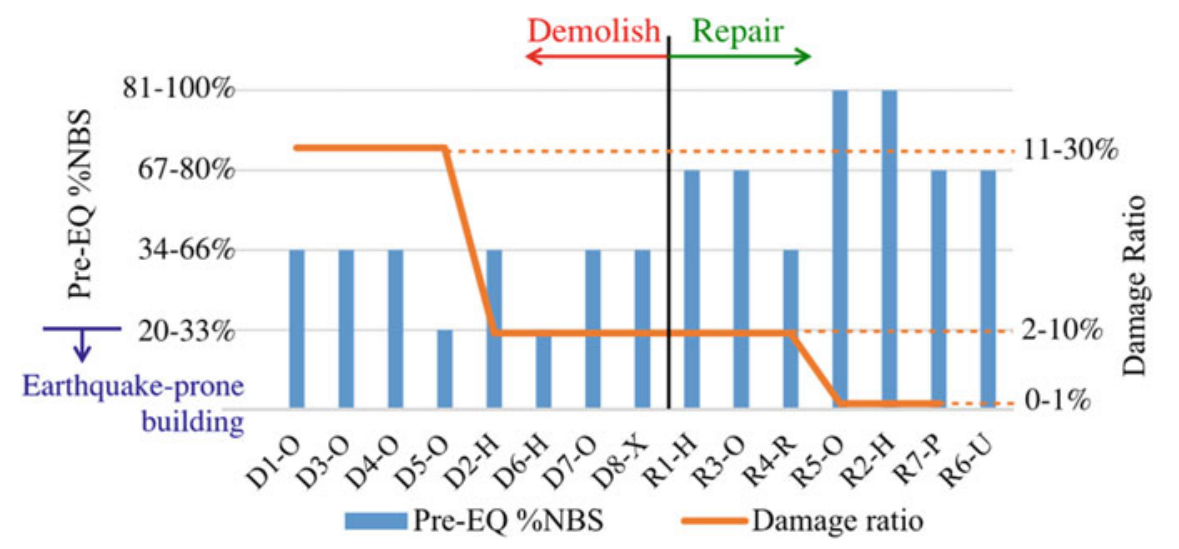

Fig. 3.5 \%NBS and damage ratio for reduced building set of 15 buildings (code on $x$-axis refers to building ID from Marquis (2015) and Marquis et al. (2017)) (figure reproduced from Kim et al. (2017))

rent commercial office market relative to Wellington and Auckland. Thus, the lower income streams generated from office buildings may have incentivized owners to demolish and rebuild differently or invest elsewhere, rather than repair following the earthquake.

Following the event, owners were faced with a number of scenarios regarding the future of their building: the building could be repaired to the same performance level, the building could be repaired to a higher standard, the building could be demolished and replaced with an equivalent building, or the building could be demolished and not replaced. In general, it was found that owner decisions were based on economics with several exceptions. Additional owner decision-making variables including business strategy, perception of risk, uncertainty, building regulations (e.g. changes in the building code, compliance issues, etc.), and government decisions (e.g. cordons, mandatory demolitions, etc.). Through interviews, it was revealed that most building owners considered it a good outcome if their building was declared a total loss and demolished, because of the financial benefits, flexibility, and speed of cash settlements. Note, however that different decision strategies were observed for some heritage building owners, where there was a preference to refurbish an old building to preserve unique architectural features or emotional attachments.

\subsubsection{Conceptual Demolish/Repair Framework}

Based on the quantitative and qualitative factors that contributed to post-earthquake decision making in Christchurch, Marquis et al. (2017) developed a comprehensive multi-phase framework (illustrated in Fig. 3.6) that summarises the demolish/repair 


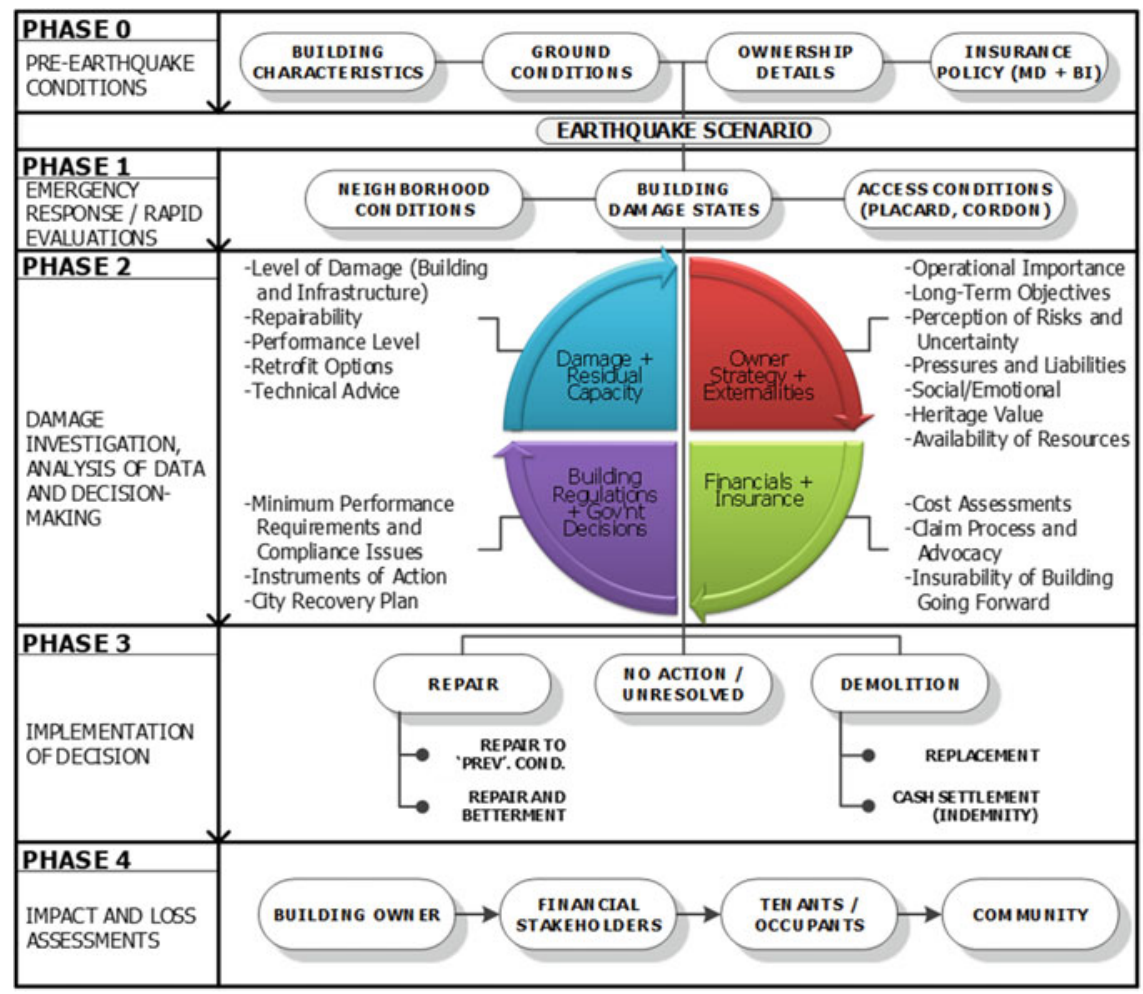

Fig. 3.6 Conceptual framework that identifies variables influencing post-earthquake decisions (figure reproduced from marquis et al. (2017))

decision making processes during and following the Canterbury earthquakes. Significant themes in the framework that were observed to be key variables that influenced decision making include: insurance, damage and residual capacity, decision making strategies, and legislation. The framework utilises a holistic approach by including a contextualisation phase (phase 0) that accounts for unique factors in the built environment or socio-economic factors that may have influenced the decision to repair or demolish. The additional phases in the framework represent the time immediately following the event through the implementation of the repair or demolition of the building.

Notably missing from the conceptual framework in Fig. 3.6 is any consideration of environmental impacts arising from building demolitions. Such impacts could be indicated in Fig. 3.6 under "Externalities" but were not highlighted by any stakeholders interviewed by Marquis et al. (2017) as influencing decision making. It is more likely that "Government Regulations" designed to de-incentivize demolitions based on environmental impacts would be needed to force this consideration into the decision-making framework. To rationalize any such regulations, it is critical 
to demonstrate the expected environmental impacts from building demolitions as described in the next section for buildings in Christchurch.

\subsection{Quantification of Environmental Impacts of Demolitions}

The afore-summarised studies that evaluated the factors that contributed to the repair or demolition of buildings following the Canterbury earthquakes revealed that the environmental impacts of demolishing repairable buildings before the end of their design life were ignored in the decision-making process. To begin to highlight the importance of incorporating environmental considerations in the decision to demolish or repair a building following an event, this section provides a preliminary evaluation of the environmental impacts of building demolitions following the Canterbury Earthquakes. Figure 3.7 summarises a comprehensive framework for calculating the environmental impacts associated with demolishing a building. The environmental impacts in the framework are broken into three distinct modules, namely: (1) embodied $\mathrm{CO}_{2}$ and energy in the building materials, (2) impacts of the processes used in construction of the building, and (3) impacts of the transport and waste management processes after demolition. This initial study focuses on the embodied $\mathrm{CO}_{2}$ and energy in the building materials (module 1 in Fig. 3.7) assuming a like-for-like replacement of materials that were demolished considering only the manufacturing of the materials, whilst excluding wider impacts of construction methods, repair (as an alternative to demolition), and waste management (in the case of demolition). These more complex factors will be incorporated in future studies.

The 142 demolished buildings from Building Set A (described above) and BRANZ $\mathrm{CO}_{2}$ NSTRUCT v1.0. (BRANZ 2019) were used to perform the preliminary environmental impact study. BRANZ $\mathrm{CO}_{2}$ NSTRUCT provides estimates for embodied $\mathrm{CO}_{2}$ and energy in common structural (e.g. in-situ concrete, precast concrete, structural steel, etc.) and nonstructural (e.g. insulation, walls, glass, paint, etc.) components

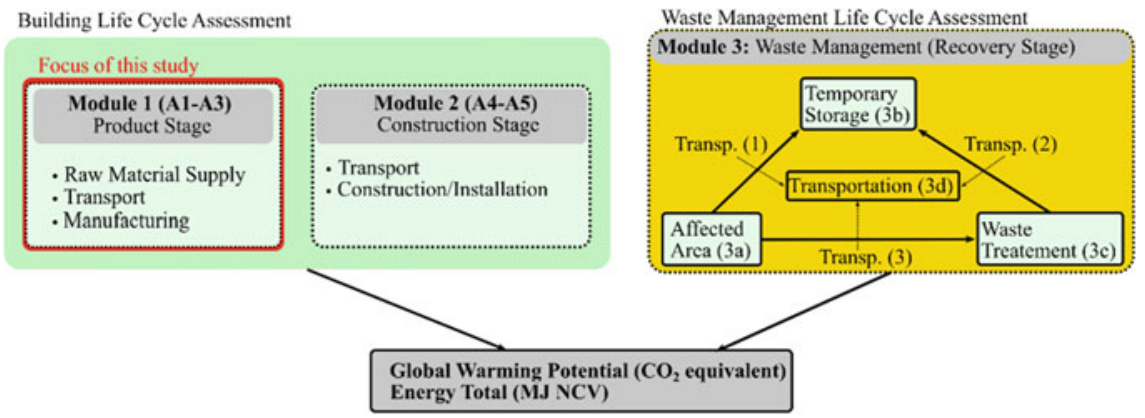

Fig. 3.7 Framework for calculating environmental impacts of building demolition 
as a function of the total weight of the components in the building. The embodied carbon is a measure of greenhouse emissions converted to units of $\mathrm{CO}_{2}$ equivalents which results from combustion of fossil fuels or chemical reactions that occur during material production, while the embodied energy considers fossil fuel, nuclear and/or renewable energy consumed in the material production (FEMA 2012).

To use the tool to determine the total embodied $\mathrm{CO}_{2}$ and energy within the structural components of a concrete building, a material takeoff is required including the volume, material strength, and reinforcing ratio of in-situ and precast concrete components and shear walls. As detailed material takeoffs were not available for all 142 demolished buildings within Buildings Set A, a subset of 9 buildings were used to develop a material takeoff prediction model that could be applied across the entire building set. A summary of several key properties of the 9 buildings in the reduced set are given in Table 3.2 (including LLRS, number of storeys, year of construction and gross floor area (GFA)), while material takeoffs from the structural components in these buildings are summarised in Table 3.3 and Fig. 3.8. Note that several simpli-

Table 3.2 Reduced building set used to develop material takeoff model

\begin{tabular}{l|l|l|l|l}
\hline Building & LLRS & Storeys & Year constructed & GFA, $\mathrm{m}^{2}$ \\
\hline 1 & MRF & 5 & 1986 & 1770 \\
\hline 2 & MRF & 5 & 1976 & 1158 \\
\hline 3 & MRF & 3 & Pre 1965 & 895 \\
\hline 4 & MRF & 12 & 1970 & 7914 \\
\hline 5 & SW & 5 & 1976 & 1433 \\
\hline 6 & SW & 4 & 1976 & 2703 \\
\hline 7 & SW & 6 & 1978 & 1603 \\
\hline 9 & SW & 9 & 1987 & 5151 \\
\hline
\end{tabular}

Table 3.3 Material takeoff of reduced building set in percentage of total weight

\begin{tabular}{l|l|l|l|l}
\hline Building & Foundations (\%) & Beams, columns, slabs (\%) & Precast & Walls (\%) \\
\cline { 4 - 5 } & & & $(\%)$ & \\
\hline 1 & 37 & 41 & 9 & 13 \\
\hline 2 & 19 & 60 & 6 & 14 \\
\hline 3 & 16 & 77 & 0 & 7 \\
\hline 4 & 28 & 63 & 5 & 3 \\
\hline 5 & 25 & 65 & 9 & 0 \\
\hline 6 & 35 & 56 & 6 & 2 \\
\hline 7 & 25 & 59 & 7 & 8 \\
\hline 8 & 45 & 39 & 12 & 4 \\
\hline 9 & 16 & 74 & 0 & 10 \\
\hline
\end{tabular}




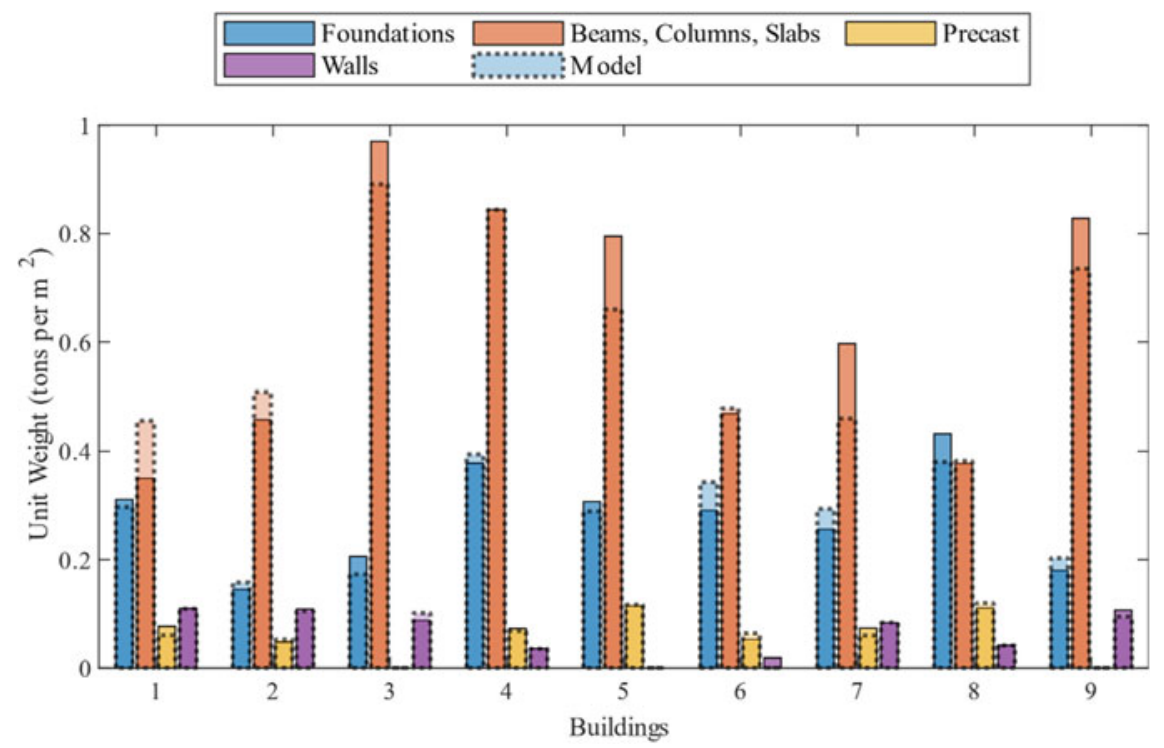

Fig. 3.8 Measured and estimated material takeoffs

fying assumptions were made when developing the material takeoffs. Namely, the volumetric reinforcing ratio, $\rho_{\mathrm{v}}$, was assumed to be $1 \%$ for in-situ cast foundations, $1.5 \%$ for in-situ cast beams, columns and slabs, $1.5 \%$ for precast beams and columns and $1 \%$ for precast panels and slabs. In addition, concrete walls that were identified as part of the primary LLRS were designated as reinforced with a reinforcing ratio of $1.5 \%$ while infill concrete walls were designated as unreinforced. The strengths of all concrete components were assumed to be consistent for all components in each building, and were defined based on recommendations from (MBIE 2018) which provides estimates for concrete strength based on year of construction.

A linear regression was used to fit independent takeoff prediction models for each of the four material subsets described above (e.g. in-situ foundations with $\rho_{\mathrm{v}}=$ $1 \%$, in-situ beams, columns, slabs with $\rho_{\mathrm{v}}=1.5 \%$, precast $\rho_{\mathrm{v}}=1.5 \%$ (beams and columns), $\rho_{\mathrm{v}}=1 \%$ (slabs and panels), and walls) as a function of gross floor area in the building. These regression models were combined into a single conditional regression model (Eq. 3.1), where GFA is the gross floor area in $\mathrm{m}^{2}, W_{m a t}$ is the weight of the material in tonnes, and the coefficients $A$ and $B$ are a function of the characteristics of the building and are summarised in Table 3.4.

$$
\mathrm{Wmat}=\mathrm{A} \times \mathrm{GFA}+\mathrm{B}
$$

The accuracy of the material takeoff model was evaluated using the reduced set of 9 buildings taken from Building Set A. The predicted material takeoffs are compared to the measured takeoffs in Fig. 3.8. In general, the model was fairly effective in predicting the material takeoffs for the 9 buildings, with an average 
Table 3.4 Regression coefficients for Eq. 3.1

\begin{tabular}{l|l|l}
\hline Condition & A & B \\
\hline Spread foundation (in-situ, $\left.\rho_{\mathrm{v}}=1 \%\right)$ & 0.108 & 58.91 \\
\hline Raft foundation (in-situ, $\rho_{\mathrm{v}}=1 \%$ ) & 0.328 & 56.67 \\
\hline Pile cap (in-situ, $\rho_{\mathrm{v}}=1 \%$ ) & 0.420 & 206.15 \\
\hline Beams and columns in building with structural walls (in-situ, $\left.\rho_{\mathrm{v}}=1.5 \%\right)$ & 0.275 & 551.83 \\
\hline Beams and columns in buildings without structural walls & 0.744 & -305.52 \\
\hline Floor or panels (precast) & 0.070 & -16.77 \\
\hline Beams or columns (precast) & 0.053 & 0 \\
\hline Walls (with precast panels) & 0.023 & 100.55 \\
\hline Walls (without precast panels) & 0.117 & -13.03 \\
\hline
\end{tabular}

percent difference of $4.5 \%$ across all materials. Larger discrepancies in individual materials (e.g. in building 1 for beam, columns, slabs) was a result of the use of precast elements not seen in the other buildings. Building 1 had precast slabs, which significantly reduced the measured volume of in-situ concrete for slabs, but increased the measured volume of precast concrete. The model respectively overpredicted and underpredicted these volumes.

The embodied $\mathrm{CO}_{2}$ and energy in the structural components of the 142 demolished buildings from Building Set A were calculated using the material takeoff model in

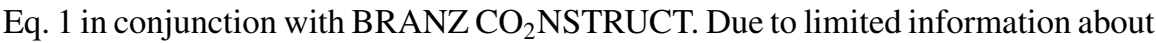
the non-structural systems in the buildings, the contribution from non-structural components (including glazing and frames, mechanical, electrical and plumbing (MEP), and tenant improvements) were accounted for using values from literature (Carbon Leadership Forum 2019; Dowdell and Berg 2016). Note that data from the Carbon Leadership Forum (2019) was developed based on US building data.

The embodied $\mathrm{CO}_{2}$ and energy calculated for each of the 142 demolished buildings are summarised Fig. 3.9, while contributions of the different material categories are summarised in Fig. 3.10. There was no apparent correlation between the primary LLRS and the embodied $\mathrm{CO}_{2}$ or energy as indicated in Fig. 3.9, and the primary embodied $\mathrm{CO}_{2}$ and energy contributor across the entire demolished building set was in-situ cast concrete as indicated in Fig. 3.10.

The total embodied $\mathrm{CO}_{2}$ and energy across all 142 demolished buildings in Building Set A reveals the large environmental impact of post-earthquake demolitions. For context, the total embodied $\mathrm{CO}_{2}$ across the demolished building set was $3.08 \times 10^{8} \mathrm{~kg}$, which is approximately equal to the annual $\mathrm{CO}_{2}$ emissions of purchased electricity in 400,000 average homes in New Zealand (Isaacs et al. 2010; Ministry for the Environment 2019). However, these values alone don't necessarily provide justification for incorporating environmental impacts into the decision to repair or demolish a building following an event, as some demolitions are unavoidable due to severe structural damage or residual deformation. To evaluate the environmental impacts of the demolition of relatively undamaged buildings in Christchurch, 


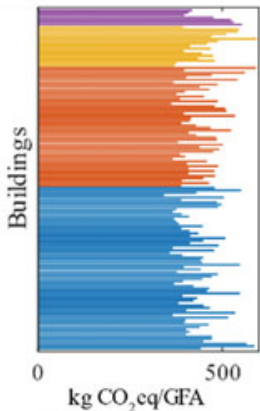

a) Embodied carbon

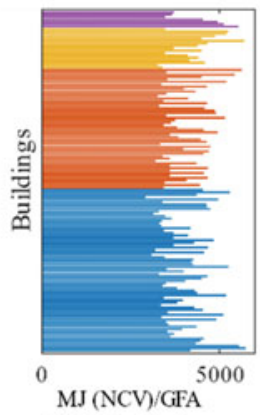

b) Embodied energy
Combined Moment Frame and Shear Walls

Average $=472.2 \mathrm{~kg} \mathrm{CO}_{2}$ eq $/ \mathrm{GFA}$

Average $=4428.9 \mathrm{MJ}(\mathrm{NCV}) / \mathrm{GFA}$

Moment Frame with Infill

Average $=462.1 \mathrm{~kg} \mathrm{CO}$ eq $/$ GFA

Average $=4331.8 \mathrm{MJ}(\mathrm{NCV}) / \mathrm{GFA}$

Shear Walls

Average $=446.1 \mathrm{~kg} \mathrm{CO}_{2}$ eq $/ \mathrm{GFA}$

Average $=4120.8 \mathrm{MJ}(\mathrm{NCV}) / \mathrm{GFA}$

Moment Frame

Average $=438.0 \mathrm{~kg} \mathrm{CO}$ eq $/ \mathrm{GFA}$

Average $=4057.9 \mathrm{MJ}(\mathrm{NCV}) / \mathrm{GFA}$

Fig. 3.9 a Embodied carbon and b Energy normalised by gross floor area of 142 demolished buildings from Building Set A

Environmental Impact A1-A3

Total Embodied carbon $=3.08 \mathrm{e}+08 \mathrm{~kg} \mathrm{CO}, \mathrm{eq}$
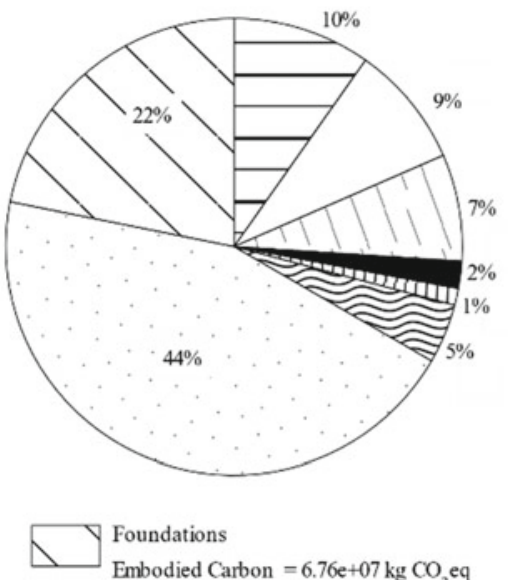

Foundations

Embodied Carbon $=6.76 \mathrm{e}+07 \mathrm{~kg} \mathrm{CO}$ eq Embodied Energy $-7.19 \mathrm{e}+08 \mathrm{MJ}$ (NCV)

$\square$ Beams, Columns, Slabs
Embodied Carbon $=1.36 \mathrm{e}+08 \mathrm{~kg} \mathrm{CO}_{2} \mathrm{eq}$ Embodied Energy $-1.56 \mathrm{e}+09 \mathrm{MJ}(\mathrm{NCV})$

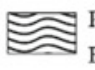

Precast Floor, Beams

Embodied Carbon $=1.47 \mathrm{e}+07 \mathrm{~kg} \mathrm{CO}$ eq Embodied Energy $=1.56 \mathrm{e}+08 \mathrm{MJ}(\mathrm{NCV})$

TाII Precast Beams, Colunns

Embodied Carbon $-3.50 \mathrm{c}+06 \mathrm{~kg} \mathrm{CO} 2 \mathrm{cq}$ Embodied Energy $=3.97 \mathrm{e}+07 \mathrm{MJ}$ (NCV)
Environmental Impact A1-A3 Total Embodied energy $=2.86 \mathrm{e}+09 \mathrm{MJ}(\mathrm{NCV})$

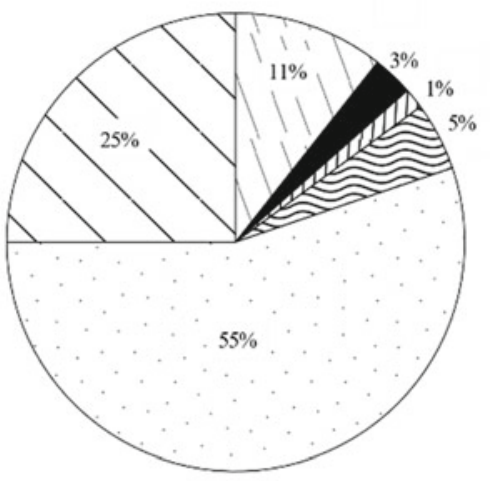

Walls

Embodied Carbon $=5.84 \mathrm{e}+06 \mathrm{~kg} \mathrm{CO}$ eq Embodied Energy $-8.08 \mathrm{e}+07 \mathrm{MJ}$ (NCV)

Glazing\&Frames

Embodied Carbon $=2.34 \mathrm{e}+07 \mathrm{~kg} \mathrm{CO}$ eq Embodied Energy $=3.05 \mathrm{e}+08 \mathrm{MJ}(\mathrm{NCV})$

Mechanical, electrical and plumbing (MEP) Embodied Carbon $=2.68 \mathrm{e}+07 \mathrm{~kg} \mathrm{CO}$ eq Embodied Energy (No data available)

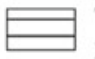

Tenant improvements (TI)

Embodied Carbon $-3.01 \mathrm{c}+07 \mathrm{~kg} \mathrm{CO} 2 \mathrm{eq}$ Embodied Energy (No data available)

Fig. 3.10 Embodied carbon and energy across 142 buildings from building set A 
the total embodied $\mathrm{CO}_{2}$ of demolished buildings across Building Set $A$ was evaluated as a function of the building damage ratios as shown in Fig. 3.11. A staggering 50\% of the total embodied $\mathrm{CO}_{2}$ in the Christchurch demolitions was from buildings with a damage ratio of less than $10 \%$, which represents a very low damage threshold that could most likely have been repaired following the event. Had these buildings been repaired rather than demolished, the savings in the total embodied $\mathrm{CO}_{2}$ across the demolished building set would have decreased significantly. However, the exact reduction cannot be calculated because there is no information regarding the type of repair which would have been necessary and the corresponding environmental cost. Considering the growing evidence that more heavily damaged buildings could likely have been repaired without safety concerns (Marder et al. 2020), it is not unreasonable to assume buildings with damage ratios up to $30 \%$ were repairable. Based on Fig. 3.11, this would suggest that nearly $80 \%$ of the total embodied $\mathrm{CO}_{2}$, or $2.45 \times$ $10^{8} \mathrm{~kg}$, was avoidable if these buildings had been repaired.

Although this provides a rough indicator as to the environmental impacts of demolishing relatively lightly damaged buildings following earthquakes, the significant savings in embodied $\mathrm{CO}_{2}$ provide a preliminary justification for incorporating environmental impacts into demolish/repair decisions following earthquakes. Furthermore, the above assessment underestimates the environmental impacts of building demolitions as it has only considered the embodied $\mathrm{CO}_{2}$ and energy in building materials. Further work by the authors will seek to include the impacts from the Construction and Waste Management Stages (Modules 2 and 3 of Fig. 3.7) in estimating the total environmental impacts of building demolitions after earthquakes.

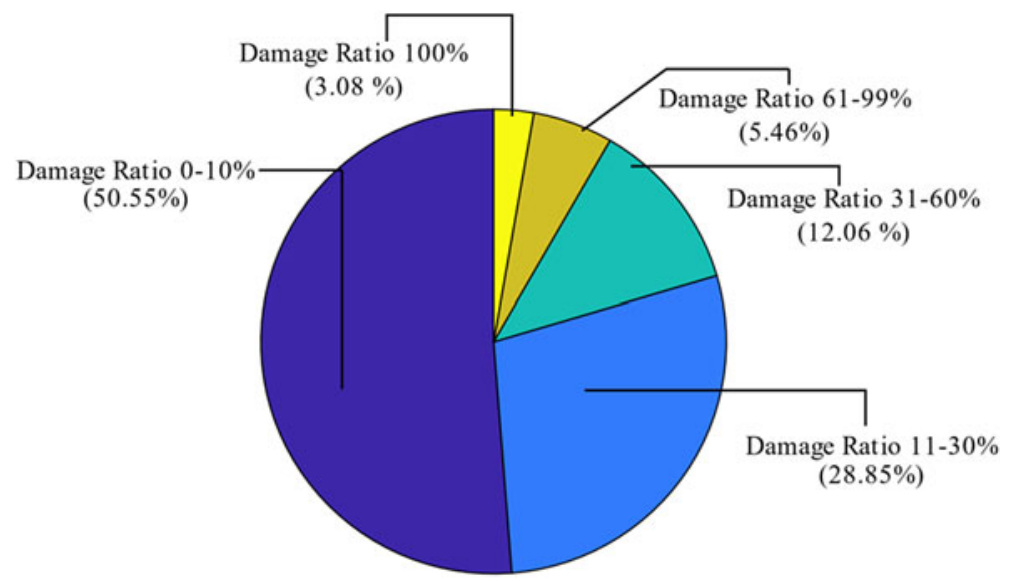

Fig. 3.11 Percentage of total embodied carbon and energy based on damage ratio 


\subsection{Summary and Conclusions}

Past studies which evaluated the complex factors that contributed to the decisions to demolish or repair buildings in Christchurch following the Canterbury Earthquakes were summarised. These studies identified a number of quantitative and qualitative factors which led to the high demolition rate including building parameters and structural damage, as well as high insurance rates, and changes and confusion in local building legislation. The review of these studies revealed that environmental impacts were neglected in the repair/demolish decision framework following the Canterbury Earthquakes. To begin to provide a justification that environmental impacts should be included in the demolish/repair framework following earthquakes, a rough quantitative assessment of the environmental impacts of building demolitions in the Christchurch CBD was conducted in terms of the embodied $\mathrm{CO}_{2}$ and energy in the building materials assuming a like-for-like replacement of materials that were demolished. Despite ignoring the wider impacts of all complex factors that influence the environmental impacts, this initial assessment revealed high environmental impacts associated with building demolitions following earthquakes. A more indepth analysis of the data revealed that a large amount of embodied $\mathrm{CO}_{2}$ in the Christchurch demolitions ( $~ 80 \%$ in the building set used here) was from buildings which were relatively lightly damaged following the event. This highlights the importance of incorporating environmental impacts into the decision to demolish or repair a building following an event, particularly if the building is relatively undamaged. The work presented here was an initial study which will be extended to include wider environmental impacts including construction methods, repair (as an alternative to demolition), waste management (in the case of demolition) including the economic viability of encouraging the diversion of deconstructed materials away from landfills.

\section{References}

Bevere L, Grollimund B (2012) Lessons from recent major earthquakes I Swiss Re

BRANZ (2019) Whole-building whole-of-life framework [WWW Document]. BRANZ CO2NSTRUCT. https://www.branz.co.nz/environment-zero-carbon-research/framework/branzco2nstruct/

Carbon Leadership Forum (2019) Estimates of embodied carbon for mechanical, electrical, plumbing and tenant improvements

Chang SE, Taylor JE, Elwood KJ, Seville E, Brunsdon D, Gartner M (2014) Urban disaster recovery in Christchurch: the central business district cordon and other critical decisions. Earthq Spectra 30:513-532. https://doi.org/10.1193/022413EQS050M

Department of Building and Housing (2011) Compliance document for New Zealand building code. Wellington, New Zealand

Dowdell D, Berg, B (2016) New Zealand wholebuilding whole-of-life framework: An overview (No. SR349). BRANZ, Wellington, New Zealand

FEMA (2012) FEMA P-58: Seismic performance assessment of buildings. Federal Emergency Management Agency, Washington D.C 
Isaacs N, Camilleri M, Burrough L, Pollard A, Saville-Smith K, Fraser R, Rossouw P, Jowett J (2010) Energy use in New Zealand households (No. SR 221). BRANZ, Wellington, New Zealand

Kam WY, Pampanin S (2011) The seismic performance of RC buildings in the 22 February 2011 Christchurch Earthquake. Struct Concr 12:223-233. https://doi.org/10.1002/suco.201100044

Kim JH (2015) Quantitative analysis of factors influencing post-earthquake decisions on concrete buildings in Christchurch. University of British Columbia, Vancouver, British Columbia, New Zealand

Kim JJ, Elwood KJ, Marquis F, Chang SE (2017) Factors influencing post-earthquake decisions on buildings in Christchurch. New Zealand. Earthq. Spectra 33:623-640. https://doi.org/10.1193/ 072516EQS120M

Marder K, Elwood KJ, Motter CJ, Clifton GC (2020) Post-earthquake assessment of moderately damaged reinforced concrete plastic hinges. Earthq Spectra 36:299-321. https://doi.org/10.1177/ 8755293019878192

Marquis F (2015) A Framework for understanding post-earthquake decisions on multi-storey concrete buildings in Christchurch. University of British Columbia, Vancouver, British Columbia, New Zealand

Marquis F, Kim JJ, Elwood KJ, Chang SE (2017) Understanding post-earthquake decisions on multi-storey concrete buildings in Christchurch, New Zealand. Bull Earthq Eng 15:731-758. https://doi.org/10.1007/s10518-015-9772-8

MBIE (2020) Building for Climate Change: Transforming the building and construction sector to reduce emissions and improve climate resilience. Ministry of Business, Innovation and Employment, Wellington, New Zealand

MBIE (2018) The Seismic assessment of existing buildings: technical guidlines for engineering assessments. Wellington, New Zealand

Ministry for the Environment (2019) Measuring emissions: a guide for organisations. 2019 Summary of emission factors. Ministry for the Environment, Wellington, New Zealand

New Zealand Supreme Court (2014) New Zealand Supreme Court (NZSC) (2014) University of Canterbury v Insurance Council of New Zealand

Parker M, Steenkamp D (2012) The economic impact of the Canterbury earthquakes. Reserve Band N Z Bull 75

Potter SH, Becker, JS, Johnston DM, Rossiter KP (2015) An overview of the impacts of the 2010 2011 Canterbury earthquakes. Int J Disaster Risk Reduct, The 2010-2011 Canterbury Earthquake Sequence: Personal, Social, Governance and Environmental Consequences 14, 6-14. https://doi. org/https://doi.org/10.1016/j.ijdrr.2015.01.014

Open Access This chapter is licensed under the terms of the Creative Commons Attribution 4.0 International License (http://creativecommons.org/licenses/by/4.0/), which permits use, sharing, adaptation, distribution and reproduction in any medium or format, as long as you give appropriate credit to the original author(s) and the source, provide a link to the Creative Commons license and indicate if changes were made.

The images or other third party material in this chapter are included in the chapter's Creative Commons license, unless indicated otherwise in a credit line to the material. If material is not included in the chapter's Creative Commons license and your intended use is not permitted by statutory regulation or exceeds the permitted use, you will need to obtain permission directly from the copyright holder.

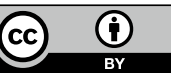

